\title{
Kinetic Model for the Study of Gene Expression in the Developing Sea Urchin
}

\author{
N. Kent Peters and Lewis J. Kleinsmith ${ }^{1}$ \\ Division of Biological Sciences, The University of Michigan, Ann Arbor, Michigan 48109
}

Received August 8, 1983; accepted in revised form November 28, 1983

\begin{abstract}
We have derived a kinetic model to assist in the study of gene expression for systems in which rapid changes in cell number occur. This kinetic model is based upon development of the sea urchin embryo, and considers changes in the number of cells, the fraction of each cell-cycle spent in mitosis, and the overall rate of transcription. We have applied this kinetic model to the accumulation of actin messenger RNA which occurs early in sea urchin embryogenesis. This analysis demonstrates that the rapid increase in cell number profoundly influences the kinetics of mRNA accumulation, and that failure to take into account the work performed by each cell can lead to significant misinterpretations of data on the expression of specific genes.
\end{abstract}

\section{INTRODUCTION}

The study of gene expression in embryonic systems is often complicated by the rapid physiological and morphological changes which take place in the developing embryo. One of the most pronounced changes that occurs is the rapid increase in the number of cells per embryo, which in turn causes a marked increase in the total amount of DNA available to serve as a template for gene transcription. If the increase in cell number takes place rapidly relative to other changes occurring in the embryo, it becomes an important parameter in the kinetics of gene expression. In the sea urchin embryo, the number of cells increases from one cell to over 500 cells in less than $24 \mathrm{hr}$ (Hinegardner, 1967). In order to evaluate the significance of this rapid increase in cell number and other alterations which influence gene transcription in the sea urchin embryo, we have developed a mathematical model to simulate these processes. The model will first be described in general terms, and will then be applied to existing data concerning actin gene expression during development.

\section{DERIVATION OF THE MODEI}

We will describe a model of gene expression for the developing sea urchin which takes into account the changes that occur in the number of cells per embryo, the transcription rate per nucleus, and the length of the cell cycle. Because in many cases we can only define how variables change with respect to each other, this model will take the form of a system of simultaneous differential equations.

\footnotetext{
${ }^{1}$ To whom correspondence should be addressed.
}

The number of cells present in the embryo of the sea urchin, Strongylocentrotus purpuratus, at different times of development was first determined by Hinegardner (1967). Our attempts to fit these available data to known growth equations such as exponential, logistic, Gompertz and others were unsatisfactory; however, we have fit these data to a set of two simultaneous differential equations of the form:

$$
\begin{aligned}
& d N / d t=\alpha N P \\
& d P / d t=-\beta N P^{2}
\end{aligned}
$$

in which $N$ is the number of cells per embryo, $P$ is the cell's potential to divide, and $t$ is time. $\alpha$ is the initial exponential growth rate constant of the embryo, and $\beta$ is the decay constant for the cell's potential to divide. The cell's potential to divide is initially set to unity, and $\alpha$ can be calculated to be $0.49 \mathrm{hr}^{-1}$ from the early data points of Hinegardner using a least-squares linear regression. Empirically, we found the growth equation fit the data best with $\beta$ equal to 0.0024 cell $^{-1} \mathrm{hr}^{-1}$. These two equations can be written as a single equation from which the nature of the growth equation is more easily appreciated

$$
d N / d t=\alpha N \exp \left(-\beta^{\prime} N\right)
$$

where $\beta^{\prime}=\beta / \alpha$. From this form of the growth equation it is apparent that the rate of cell division decays exponentially with respect to the number of cells per embryo. When this growth equation is numerically integrated and compared with the data of Hinegardner (1967), the theoretical curve accurately predicts the number of cells per embryo throughout development (Fig. 1).

As the sea urchin develops it performs work, and the amount of work performed can be measured in units of 


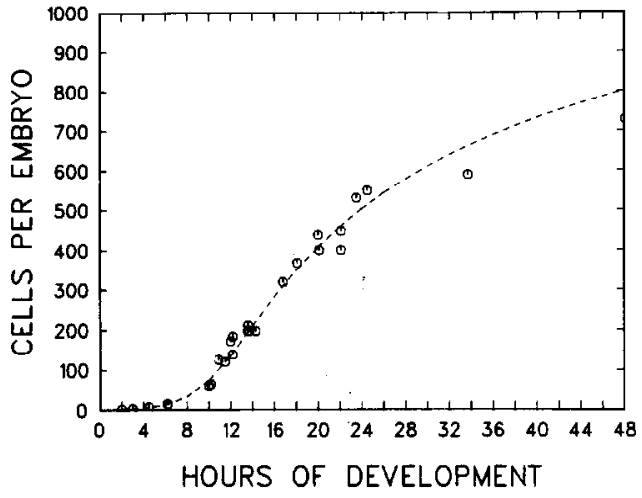

FIG. 1. Comparison of the measured number of cells per embryo throughout development with a theoretical curve generated from equations 1 and 2 . The number of cells per embryo as determined by Hinegardner (1967) is shown as $(O)$. The smooth dashed curve is a plot of the predicted number of cells per embryo $(N)$ generated by numerically integrating Eqs. (1) and (2). This two-variable growth curve accurately predicts the number of cells per embryo throughout development.

cell-hours. The equation relating cell-hours of work $(H)$ to the number of cells per embryo is

$$
d H / d t=N \text {. }
$$

This model will now be expanded to incorporate features of sea urchin embryogenesis which affect the amount of work contributing to gene transcription. Several researchers have measured the rate of transcription in the sea urchin embryo throughout development (Wilt, 1970; Wilt and Wu, 1974; Levner, 1974; Roeder and Rutter, 1970). These data indicate that the rate of transcription per cell decreases as the embryo develops. Examination of these data suggests that the rate of transcription $(T)$, like a cell's potential to divide, decays exponentially with respect to the number of cells per embryo. The exponential decay constant $(\mu)$ can be calculated from the rate of transcription data using a leastsquares linear regression and has been found to be 0.0023 cell $^{-1}$. The change in transcription rate with respect to the number of cells per embryo is thus

$$
d T / d N=-\mu T \text {. }
$$

The time derivative of $T$ is obtained using the chain rule with equations 1 and 5 , yielding

$$
d T / d t=-\mu^{\prime} N P T
$$

where $T$ is the rate of transcription per cell, and $\mu^{\prime}$ is equal to $\alpha \mu$ or $0.0011 \mathrm{cell}^{-1} \mathrm{hr}^{-1}$. The rate of transcription can be expressed in $\mathrm{pg}$ of heteronuclear RNA synthesized per hour, or as a relative value (in the present example, we have set the transcription rate of the 16-32 cell embryo equal to unity and expressed all other values relative to unity).
Another feature of sea urchin development which may influence gene expression is the length of the cell cycle. During early cleavage the cell cycle is short, and the fraction of each cell cycle spent with the chromosomes condensed is significant. Chromatin in this condensed state is transcriptionally inactive (Nemer, 1962), and thus decreases the amount of time the cell can spend transcribing gene templates into RNA. If we assume that the absolute time the chromatin is condensed is constant (approximately $0.6 \mathrm{hr}$ from prophase to anaphase according to Hinegardner et al., 1964), then as the cell cycle gets longer, the fraction of time spent with the chromatin in an active conformation increases. The length of a cell cycle is equal to $\ln (2) / \alpha P$ such that the fraction of time the cell spends with its chromatin $(C)$ in an active conformation is given by

$$
C=\frac{\ln (2) / \alpha P-\lambda}{\ln (2) / \alpha P}
$$

where $\lambda$ is the absolute time in hours the cell spends with condensed chromatin. The change in $C$ with respect to $P$ can be found from Eq. (7), and the time-dependent function of $C$ results by applying the chain rule using Eq. (2):

$$
d C / d t \doteq \rho N P^{2}
$$

where $\rho$ is equal to $\alpha \beta \lambda / \ln (2)$, or 0.0028 cell $^{-1}$.

Equation (4) defines a general work function for the embryo in cell-hours. To calculate the amount of transcriptional work performed by the embryo, we must modify Eq. (4) to include the effects of condensed chromatin and decreases in the rate of transcription as described in Eqs. (6) and (8), respectively. The following equation for transcriptional work $(W)$ relates the number of cells per embryo, the fraction of time the cell's chromatin is active, and the rate of transcription per cell.

$$
d W / d t=N T C .
$$

\section{APPLICATION OF THE MODEL}

The importance of considering changes in cell number in the embryo when evaluating gene expression will be demonstrated by applying the above concepts and equations to data collected on the quantity of actin messenger RNA present in the sea urchin embryo throughout development. Little actin messenger RNA activity can be detected in the unfertilized oocyte, but by $24 \mathrm{hr}$ of development actin constitutes approximately $5 \%$ of all protein synthesis (Merlino et al., 1981; Peters and Kleinsmith, unpublished observation). Clearly, significant amounts of actin messenger RNA must be synthesized during the developmental period following fertilization. The concentrations of two actin messenger 
RNAs, of 1.8 and 2.0 kilobases, respectively, have been observed to increase in amount dramatically between 12 and $24 \mathrm{hr}$ of development (Merlino et al., 1981). These two actin messenger RNAs then decrease in concentration during subsequent gastrulation.

When the changes in the amount of actin messenger RNA per embryo are compared to the increase in the number of cells present, it is seen that the elevation in actin mRNA that occurs between 12 and $24 \mathrm{hr}$ is proportionally greater than the increase in cells per embryo (Fig. 2). This would upon first impression imply a relative increase in the level of expression of the actin genes. This analysis is incomplete, however, because the change in actin messenger RNA has been compared only to the total number of cells contained in the embryo, and not to the total work performed by the cells of the embryo. The incompleteness of this analysis can be best demonstrated by examining the units for the transcription rate. The proper units are mass of RNA per cell per unit time. If a transcription rate is multiplied by the number of cells in the embryo, the resulting value is mass of RNA per unit time:

$$
\frac{\text { mass of RNA }}{\text { cell-hours }} \times \text { cell }=\frac{\text { mass of RNA }}{\text { unit of time }} .
$$

This demonstrates that the rate of transcription must be multiplied by cell-hours to yield the total of mass of RNA. The cell-hour represents the work function per-

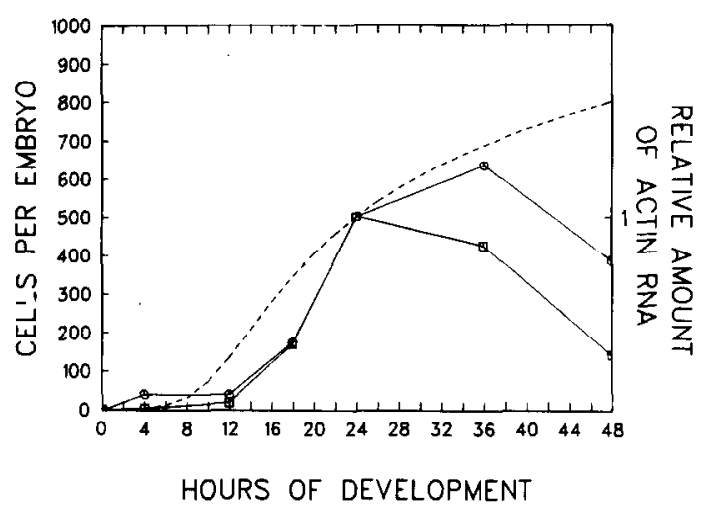

FIG. 2. Comparison of the predicted number of cells per embryo with the amount of actin messenger RNA. The measured amounts of $1.8 \mathrm{~kb}(\square)$ and $2.0 \mathrm{~kb}(0)$ actin RNAs are compared with the predicted number of cells per embryo as generated from Eqs. (1) and (2) (smooth dashed curve). In the case of the $2.0 \mathrm{~kb}$ RNA, the small amount of actin mRNA present in the egg has been subtracted from the amount of actin RNA at later times during development so that only newly synthesized actin mRNA is examined. For comparison, the values of actin mRNA have been set equal to the number of cells per embryo at $24 \mathrm{hr}$ of development. In neither case does the shape of the theoretical curve match that of the curve for the amount of actin RNA, indicating that there is no direct relationship between the number of cells per embryo and the amount of actin messenger RNA.

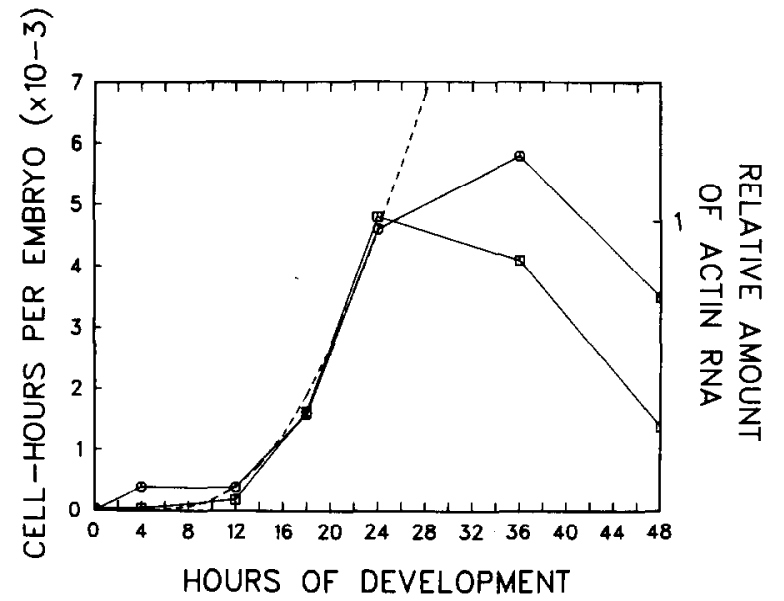

Fig. 3. Comparison of the cell-hour work function and the increase of actin messenger RNA in the developing sea urchins. The work function (smooth dashed curve) generated by numerically integrating Eqs. (1), (2), and (4) is compared with the $1.8 \mathrm{~kb}$ actin mRNA ( $\square$ ), and the $2.0 \mathrm{~kb}$ actin mRNA $(O)$. For comparison, the amount of actin mRNA at $21 \mathrm{hr}$ of development has been set equal to the number of cell-hours of work at $21 \mathrm{hr}$. In each case, the work function overlies the curve for the accumulation of the actin mRNA indicating that the kinetics for the accumulation of these RNAs are compatible with a constant transcription rate per cell. Note that even though the amount of $2.0 \mathrm{~kb}$ actin messenger RNA is only half the amount of the $1.8 \mathrm{~kb}$ actin messenger RNA at $24 \mathrm{hr}$ of development, the kinetics of their accumulation is the same.

formed by the embryo and is analogous to the concept of a wo(man)-hour. The number of cell-hours $(H)$ of work performed by the embryo through development is calculated by numerically integrating equations 1,2 , and 4. In Fig. 3, the amounts of actin mRNA are compared with this cell-hour function. The curves for the cell-hour function and the amount of actin mRNA overlie one another through $24 \mathrm{hr}$ of development. This demonstrates that the rapid increase in the amount of actin mRNA that occurs between 12 and $24 \mathrm{hr}$ of development is compatible with a constant transcription rate of actin message per cell.

To simplify the above discussion we have assumed a constant rate of transcription for the actin genes, while we know that the overall rate of transeription per nucleus decreases through development. We wish now to consider the change in transcription rate along with changes in the amount of time the chromatin spends in an active conformation. These changes are considered by the system of differential Eqs. (1), (2), (6), (8), and (9). When this system of equations is integrated numerically and the transcriptional work $(W)$ is compared to the amount of actin mRNAs (Fig. 4), the two curves still overlie one another. This indicates that the decrease in the rate of transcription does not significantly influence the overall shape of the work function because the increasing number of cell-hours is the dominating factor. 


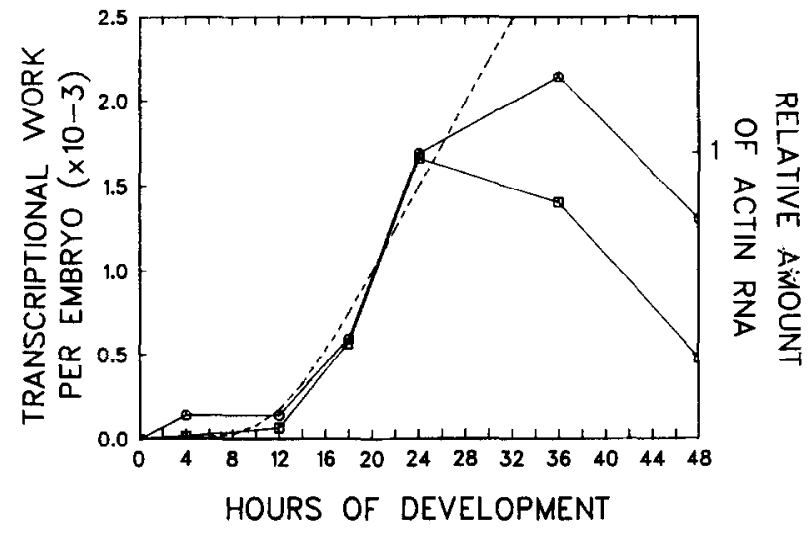

FIG. 4. Comparison of the measured amount of actin mRNA with the transcriptional work performed by the embryo. The amount of $1.8 \mathrm{~kb}(\square)$ and $2.0 \mathrm{~kb}(\mathrm{O})$ actin mRNAs is compared with the transcriptional work (smooth dashed curve) performed by the embryo as generated from Eqs. (1), (2), (6), (8), and (9). Consideration of the change in rate of transcription and the fraction of time spent in mitosis does not significantly change the shape of the curve from that of the cell-hour work function, even though the absolute values do change. The curve for transcriptional work performed overlies the curves for the accumulation of actin $\mathrm{mRNA}$, indicating that actin messenger RNA would accumulate with the same kinetics even if the rate of actin transcription decreased through the course of development.

\section{DISCUSSION}

The above analysis demonstrates how this set of differential equations can be used to examine data relating to gene expression in the developing sea urchin. The observation that the curve for the transcriptional work of the embryo overlies the curve for the accumulation of actin mRNA is consistent with the interpretation that actin messenger RNA is synthesized at a constant rate per cell relative to all RNA synthesis up until 24 $\mathrm{hr}$ of development, and that actin messenger RNA degradation is not significant until after $24 \mathrm{hr}$ of development. Of course, the close correlation between the observed and theoretical curves does not prove that our interpretation is correct; however, it is the simplest interpretation. This interpretation is not intuitively obvious, thus emphasizing the need for this set of equations to help analyze gene expression data.

After $24 \mathrm{hr}$ of development, the cell-hour curve no longer overlies the curve for the amount of actin messenger RNA. This divergence of the theoretical from the observed data indicates that additional factors have come into play, and that more data are needed to interpret the decrease in amount of actin messenger RNA. The two most obvious possibilities are that the rate of actin messenger RNA synthesis decreases and/or that the rate of degradation increases.

Shott et al. (1983) have shown that while $S$. purpuratus has six actin genes, only two of these genes, CyI and CyIIIa, produce significant amounts of transcript in the early embryo (our 1.8 and $2.0 \mathrm{~kb}$ actin messages). Our analysis is therefore not complicated by the presence of actin transcripts other than the two we have been considering. As mentioned in the legend to Fig. 3, the amount of $2.0 \mathrm{~kb}$ actin messenger RNA is only half the amount of $1.8 \mathrm{~kb}$ actin RNA at $24 \mathrm{hr}$ of development. This observation might seem to invalidate our assumption that the two actin messenger RNAs are synthesized at the same constant rate per cell relative to all RNA synthesis. However, it has been found that the 1.8 and $2.0 \mathrm{~kb}$ actin messenger RNAs are selectively expressed in the ectoderm and endoderm/mesoderm respectively (Peters and Kleinsmith, unpublished observations). Since there are half as many cells in the endoderm/ mesoderm as there are in the ectoderm (Bruskin et al., 1981 ), there are half as many cells synthesizing the 2.0 $\mathrm{kb}$ message as the $1.8 \mathrm{~kb}$ actin message. Thus the transcriptional work performed by the embryo is simply partitioned to reflect the number of cells producing each actin transcript.

Not all messenger RNAs behave in the same manner as the actin messenger RNAs which we have been considering. Accumulation of histone messenger RNA, for example, does not follow the cell-hour function, but rather is proportional to the change in the number of cells per embryo (Nemer et al., 1975). Likewise, other messenger RNAs have also been found to exhibit specific patterns of localization and kinetics (Bruskin et al, 1981). The model described in this paper can be used to ascertain what kinds of regulation may be occurring with these different types of transeripts. Although the equations we have developed are specific for the sea urchin embryo, the principles used to construct this model can also be applied to other developmental systems in which the number of cells changes rapidly.

We would like to thank Michael Savageau, Chuck Scott, and Eberhard Voit for their insights and encouragement. We are also indebted to Michael Savageau for the use of his computer simulation program, Symbiosis. A special thanks goes to Mary Zeigler and Leslie Wanner who kindly commented on the manuscript. N.K.P. is supported by NIH training grant 1-P32-GM 07544-05. A portion of this work was supported by NSF Grant PCM 78-15300.

\section{REFERENCES}

Bruskin, A. M., Tyner, A. L., Wells, D. E., Showman, R. M., and KLEIN, W. H. (1981). Accumulation in embryogenesis of five mRNAs enriched in the ectoderm of the sea urchin pluteus. Develop. Biol. 87, 308-318.

Crain, W. R., Jr., Durica, D. S., and Van Doren, K. (1981). Actin gene expression in developing sea urchin embryos. Mol. Cell. Biol. $1,711$. 
HiNEgaRDNeR, R. T. (1967). Echinoderms. In "Methods in Developmental Biology" (F. H. Wilt and N. K. Wessells, eds.), p. 139. CrowellCollier, New York.

Hinegardner, R. T., RaO., B., and Feldman, D. E. (1964). The DNA synthetic period during early development of the sea urchin egg. Exp. Cell. Res. 36, 53.

LEVNER, M. H. (1974). RNA transcription in mature sea urchin eggs. Exp. Cell. Res. 85, 296.

NEMER, M. (1962). Characterizations of the utilization of nucleosides by embryos of Paracentrotus lividus. J. Biol. Chem 237, 143.

Nemer, M., (1975). Developmental changes in the synthesis of sea urchin embryo messenger RNA containing and lacking polyadenylic acid. Cell 6, 599.
Merlino, G. T., Water, R. D., Moore, G. P., and KLeinsmith, L. J. (1981). Change in expression of the actin gene family during early sea urchin development. Develop Biol. 85, 505.

ROEDER, R. G., and RUTTER, W. J. (1970). Multiple forms of RNA polymerases and RNA synthesis during sea urchin development. Biochemistry 9, 2543.

ShotT, R. J., LeE, J. J., Britten, R. J., and Davidson, E. H. (1983). Differential expression of the Actin gene family of Strongylocentrotus purpuratus. Develop. Biol. 101, 295.

WILT, F. H. (1970). The acceleration of ribonucleic acid synthesis in cleaving sea urchin embryos. Develop. Biol. 23, 444.

Wu, R. S., and WILT, F. H. (1974). The synthesis and degradation of RNA containing polyriboadenylate during sea urchin embryogeny. Develop. Biol. 41, 352. 